\author{
Military Technical College \\ Kobry Elkobbah, Cairo, \\ Egypt.
}

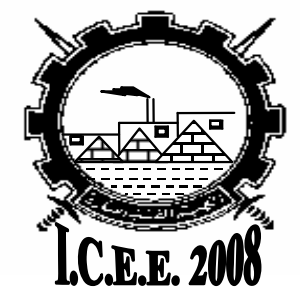

$4^{\text {th }}$ International Conference

On

Chemical \& Environmental

Engineering

27-29 May 2008

\title{
APPLICATION OF HPLC FOR THE ANALYSIS OF MALATHION AND S-MUSTARD MIXTURE
}

\author{
KASSEM* M, FAYED* M., Soltan* A. and El Ahmad ${ }^{* *}$ L. A.
}

\begin{abstract}
A method was developed for the chromatographic separation and quantification for a mixture of Malathion (as organophosphorus nerve agent), and S-mustard (as blister agent). The method used a high performance liquid chromatography (HPLC) with reversed phase C-18 column, and UV detection at $220 \mathrm{~nm}$. The compounds were separated using isocratic elution acetonitrile-water $(50 \%)$ at a flow rate of $0.7 \mathrm{~mL} / \mathrm{min}$ in a period of $5 \mathrm{~min}$. The retention times were (1.939) min for S-mustard and (3.063) min for Malathion. The calibaration curves were linear $\left(R^{2}=0.999\right)$ in the studied concentration range (200 to $1000 \mu \mathrm{g} / \mathrm{mL}$ ). Sensitivity of the method for quantification of Malathion was found to be higher than that of S-mustard by four times. In addition, the accuracy was found to be $(\sim 97 \%)$ for both.
\end{abstract}

\section{KEY WORDS}

Malathion, S-mustard, HPLC analysis,

\footnotetext{
${ }^{*}$ Egyptian Army Forces

** Syrian Army Forces
} 


\section{INTRODUCTION}

Detection of chemical warfare agents (CWAs) in times of war or in acts of terrorism requires rapid and reliable methods. In recent years there has been a growing interest in the analysis of CWAs as well as their precursors, manufacturing byproducts and degradation products. This is mainly because of the coming into force of the Chemical Weapons Convention (CWC), which prohibits the development, production, stockpiling and use of CWAs [1]. Analysis of CWAs and related compounds may play a key role in the verification of the treaty; the destruction of existing stockpiled CWAs has to be carefully followed by a special analytical procedures.

The most significant chemical warfare agents in terms of military capacity and past use are the nerve and blister agents [2].

The common chemical warfare agents have varying degrees of volatility and dose, both a vapor hazard as well as a liquid contact hazard. This physical characteristic has made the analysis of chemical warfare agents amenable to the analytical techniques commonly employed for most environmental analyses, namely gas chromatography (GC) and liquid chromatography (LC) with a variety of detectors including mass spectrometry (MS) [3-5].

High pressure liquid chromatography (HPLC) can be employed not only for separation but also for identification, of different compounds by comparing the retention time of the unknown compound to that of a known one (standard) under the same operating conditions. However, HPLC technique can be used as qualitative and quantitative method of identification of organic compounds through retention time and peak area respectively [6].

\section{EXPERIMENTAL WORK}

\section{Chemicals.}

S-mustard (HD) was prepared in laboratory by Clark's method [7] and then it was purified by vacuum distillation. The obtained product has about $95 \%$ purity. Malathion 95\% was obtained from (Nasr Company for intermediate chemicals). Ethanol 95\% (UCCMA), acetonitrile HPLC grade (Aldrich), deionized water HPLC grade (Fluka).

\section{INSTRUMENTATION}

HPLC Agilent 1100 series equipped with auto sampler. HPLC column $(150 \mathrm{~mm} \times 2.1$ $\mathrm{mm}$ ID) reversed phase Zorbax SB C-18 column with guard column. HPLC detector: UV-Vis diode array detector (DAD). All system parameters can be automatically controlled through HP 3DLC Chemistation software. 


\section{Operating Conditions}

$\begin{array}{ll}\text { Mobile Phase: } & \text { Acetonitrile }(50 \%) \text { - Water (50\%). } \\ \text { Flow rate: } & 0.7 \mathrm{~mL} / \mathrm{min} . \\ \text { Elution: } & \text { Isocratic } \\ \text { Injection volume: } & 10 \mu \mathrm{\mu l} \\ \text { Detector: } & \text { UV Detector at } 220 \mathrm{~nm} . \\ \text { The stop time: } & 5 \mathrm{~min} . \\ \text { Column temperature: } & 35^{\circ} \mathrm{C}\end{array}$

\section{Stock And Standard Solutions}

A stock solution of $(8.12 \mathrm{mg} / \mathrm{mL})$ S-mustard in ethanol $95 \%$ was obtained by dissolving $406 \mathrm{mg}$ of S-mustard in $50 \mathrm{~mL}$ of ethanol. This solution was used as external standard for determination the retention time of S-mustard. The chromatogram of S-mustard is shown in Fig. (1).

A stock solution of $(10 \mathrm{mg} / \mathrm{mL})$ Malathion was prepared by dissolving $100 \mathrm{mg}$ of Malathion in $10 \mathrm{~mL}$ of ethanol $95 \%$. By accurate dilution $1 \mathrm{mg} / \mathrm{mL}$ solution of Malathion in ethanol was prepared. This solution was used as external standard for determination of the retention time of Malathion. The chromatogram of Malathion is shown in Fig. (2).

A stock solution of $(2 \mathrm{mg} / \mathrm{mL})$ S-mustard in ethanol was obtained by dissolving $20 \mathrm{mg}$ of S-mustard in $10 \mathrm{~mL}$ of ethanol.

A stock solution of $(2 \mathrm{mg} / \mathrm{mL})$ Malathion in ethanol was obtained by dissolving $20 \mathrm{mg}$ of Malathion in $10 \mathrm{~mL}$ of ethanol.

A mixture of S-mustard and Malathion was prepared by mixing $5 \mathrm{~mL}$ of $2 \mathrm{mg} / \mathrm{mL} \mathrm{S}$ mustard solution in ethanol with $5 \mathrm{~mL}$ of $2 \mathrm{mg} / \mathrm{mL}$ Malathion solution in ethanol. The obtained mixture is of $1 \mathrm{mg} / \mathrm{mL}$ concentration for S-mustard and Malathion. This mixture was used for preparation the calibration standards. The chromatogram of the mixture of S-mustard and Malathion is shown in Fig. (3).

\section{Calibration Curves}

For quantitative analysis of S-mustard and Malathion in the mixture, five standards were prepared as follows:

Different volumes $(0.2,0.4,0.6,0.8$ and $1 \mathrm{~mL})$ of the $1 \mathrm{mg} / \mathrm{mL}$ mixture solution were delivered into $2 \mathrm{~mL}$ caped vials and completed to $1 \mathrm{~mL}$ with ethanol. The obtained calibration standards were containing concentrations of $(200,400,600,800$ and $1000 \mu \mathrm{g} / \mathrm{mL}$ ). Each calibration standard was analyzed by HPLC, and the peak area of S-mustard and Malathion was plotted for each standard against concentration. Two calibration curves are obtained, the first for S-mustard Fig. (4) and the second for Malathion Fig. (5). 


\section{Sensitivity And Accuracy Of The Method}

Sensitivity of this method is considered as the value of the slope of the calibration curve which is shown in Fig. (4) for S-mustard, and the value of the slope of calibration curve which is shown in Fig. (5) for Malathion.

For determination of the accuracy of this method, a mixture of S-mustard and Malathion of concentration $500 \mu \mathrm{g} / \mathrm{mL}$ was prepared and quantitatively analyzed by HPLC at the same operating conditions, and then the accuracy was calculated[6].

\section{RESULTS AND DISCUSSION}

\section{Chromatogram}

The chromatogram shown in Fig. (3) contains two main peaks which are separated with good resolution. The first peak located at retention time 1.939 min. which represents the S-mustard and the second peak located at retention time $3.063 \mathrm{~min}$. which represent the Malathion. These qualitative identifications were done by comparing retention time with that of a standard under the same operating conditions as shown in Fig. $(1,2)$. The peak located at retention time 1.547 min represents the impurities of Malathion. The peak located at retention time 0.886 min represents thiodiglycol which is the hydrolysis product of sulphur mustard. The peak located at retention time 0.565 min represents the ethanol which is the used solvent. S-mustard and Malathion were separated with good resolution as it is shown in Fig. (3).

\section{Calibration Curves}

For quantitative analysis of the mixture of S-mustard and Malathion, two calibration curves were constructed as described before, the first for S-mustard, Fig. (4) and the other for Malathion, Fig. (5). The two calibration curves have good linearity $\left(R^{2}=\right.$ $0.999)$ over the studied concentration range $(200-1000) \mu \mathrm{g} / \mathrm{mL}$.

\section{Sensitivity And Accuracy}

The comparison between the slope values on the concentration range (200-1000) $\mu \mathrm{g} / \mathrm{mL}$ for the two calibration curves show that, the sensitivity of quantification of Malathion by this analytical method is higher than that of S-mustard by four times.

The accuracy was determined by quantitative evaluation of a known concentration, of S-mustard and Malathion mixture. The mixture of S-mustard and Malathion has the concentration of $500 \mu \mathrm{g} / \mathrm{mL}$ for both. The measured peak areas were (956) for Smustard and (4556) for Malathion. By using the constructed calibration curves, the obtained concentrations were $(514.34 \mu \mathrm{g} / \mathrm{mL})$ for S-mustard and $(515.85)$ for Malathion which give accuracy $(\sim 97 \%)$.

\section{CONCLUSION}

An HPLC method was developed for the analysis of S-mustard and Malathion. The constructed calibration curve using this method was linear $\left(R^{2}=0.999\right)$ over the studied concentration range (200 and $1000 \mu \mathrm{g} / \mathrm{mL})$. The sensitivity of quantification of 
Malathion by this method is higher than that of S-mustard by four times. The accuracy of this method was found to be $(\sim 97 \%)$ for both.

\section{REFERENCES}

[1] "Chemical weapons convention ", accessible through internet http://en.wikipedia.org/wiki/chemical-warfare.

[2] "Potential military chemical/biological agents and compounds", USA army, Reid Kirby, ISBN 0-9677264-0-9, 2005.

[3] Kientz, Ch.E. "Chromatography and mass spectrometry of chemical warfare agents, toxins and related compounds: State of the art and future prospects", J.Chromatogr.A, 814, 1-23, 1998.

[4] Edwin W.J. Hooijschuur, Charles E. Kientz, Udo A.Th.Brinkman, "Analytical separation techniques for the determination of chemical warfare agents", Journal of Chromatography A, 982, 177-200, 2002.

[5] P.A. D Agostino and C.L. Chenier, DRDC Suffield, "Analysis of chemical warfare agents; General overview, LC-MS review, In-house LC-ESI-MS methods and open literature bibliography", 2006.

[6] David Harvey, "Modern analytical chemistry", McGraw-Hill, USA, 2000.

[7] Sartory A., "Chemistry and Analysis of War Gases" Italy, 1940. 

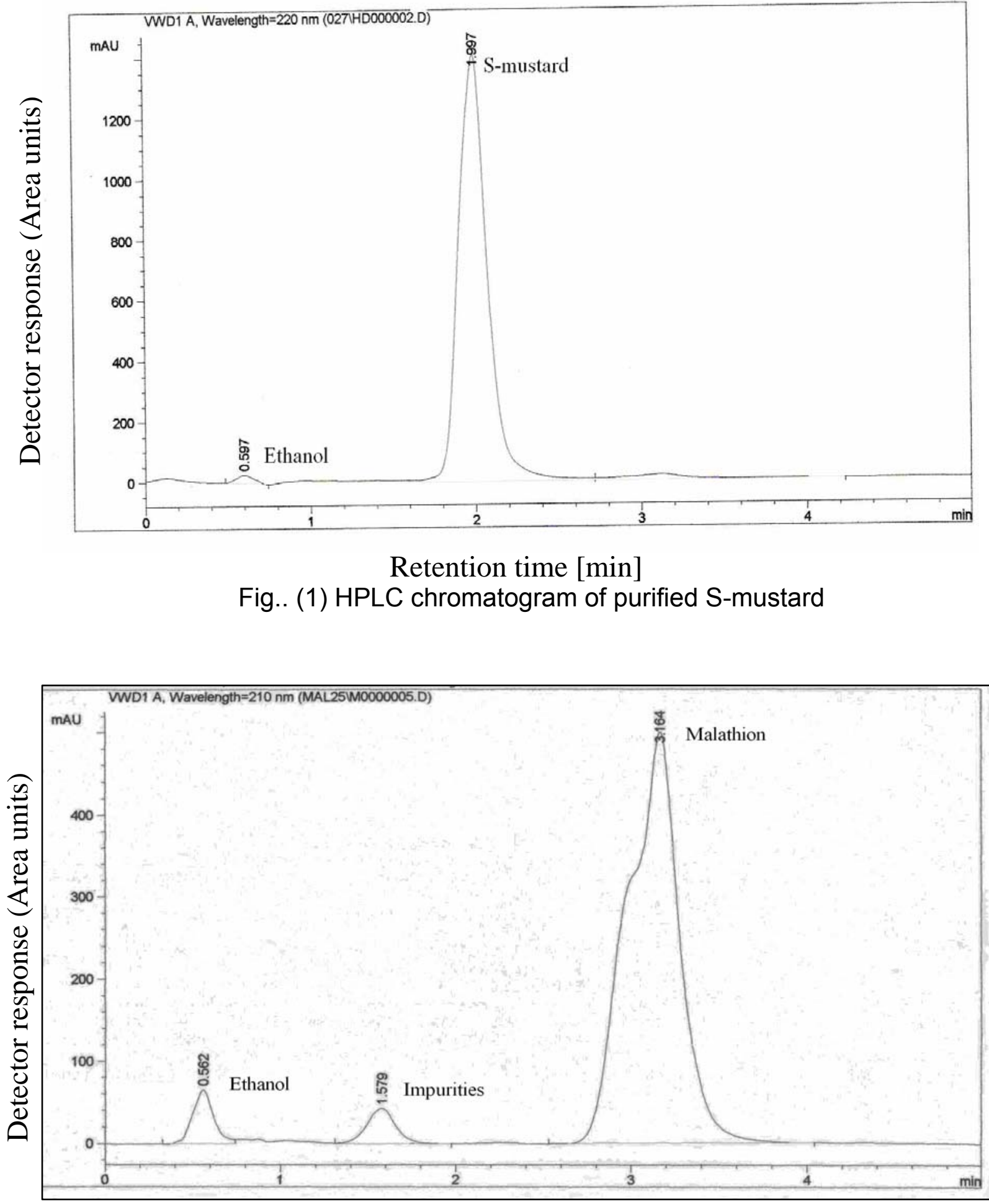

Retention time [min]

Fig. (2) HPLC chromatogram of Malathion. 


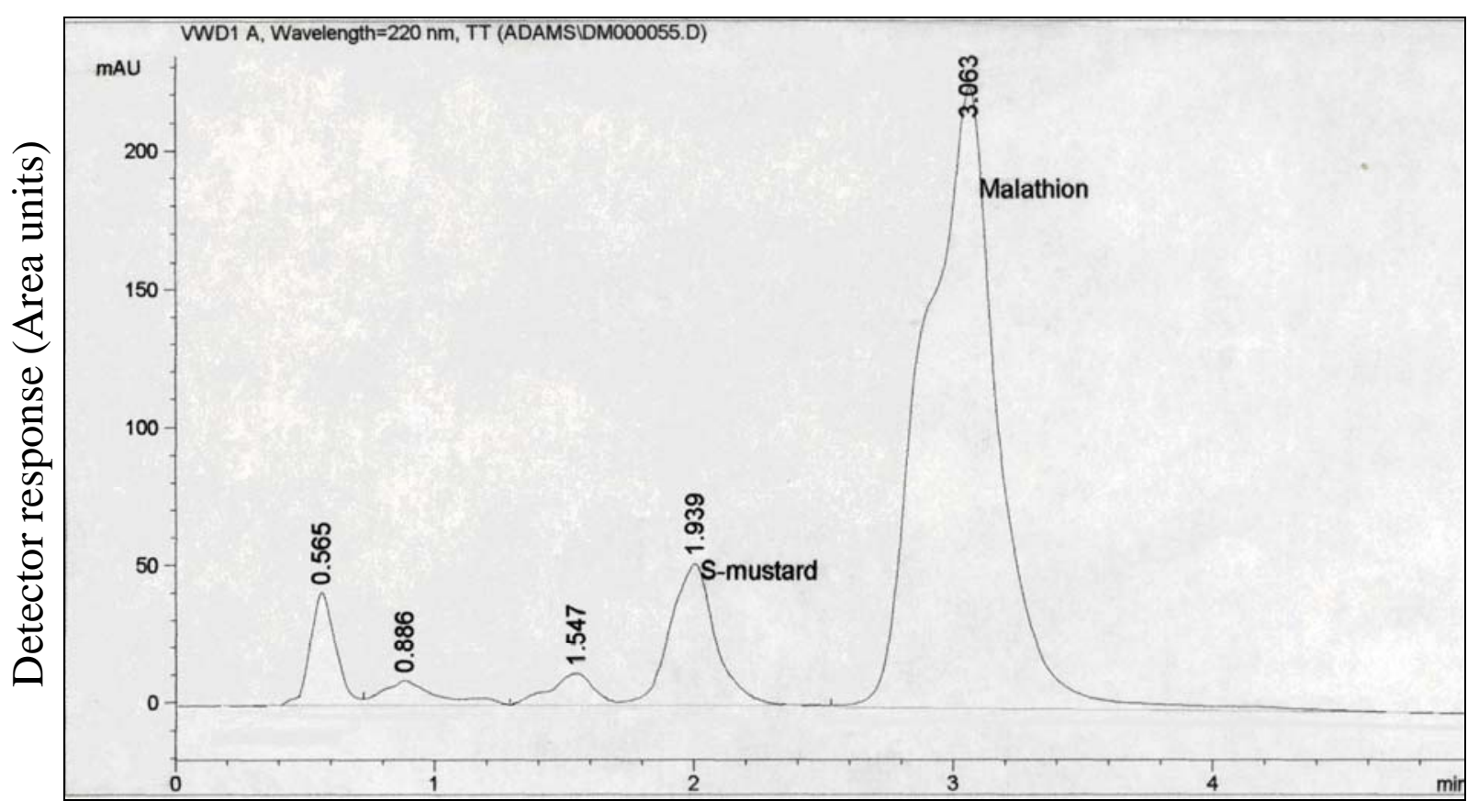

Retention time [min]

Fig.. (3) HPLC chromatogram for a mixture of S-mustard and Malathion.

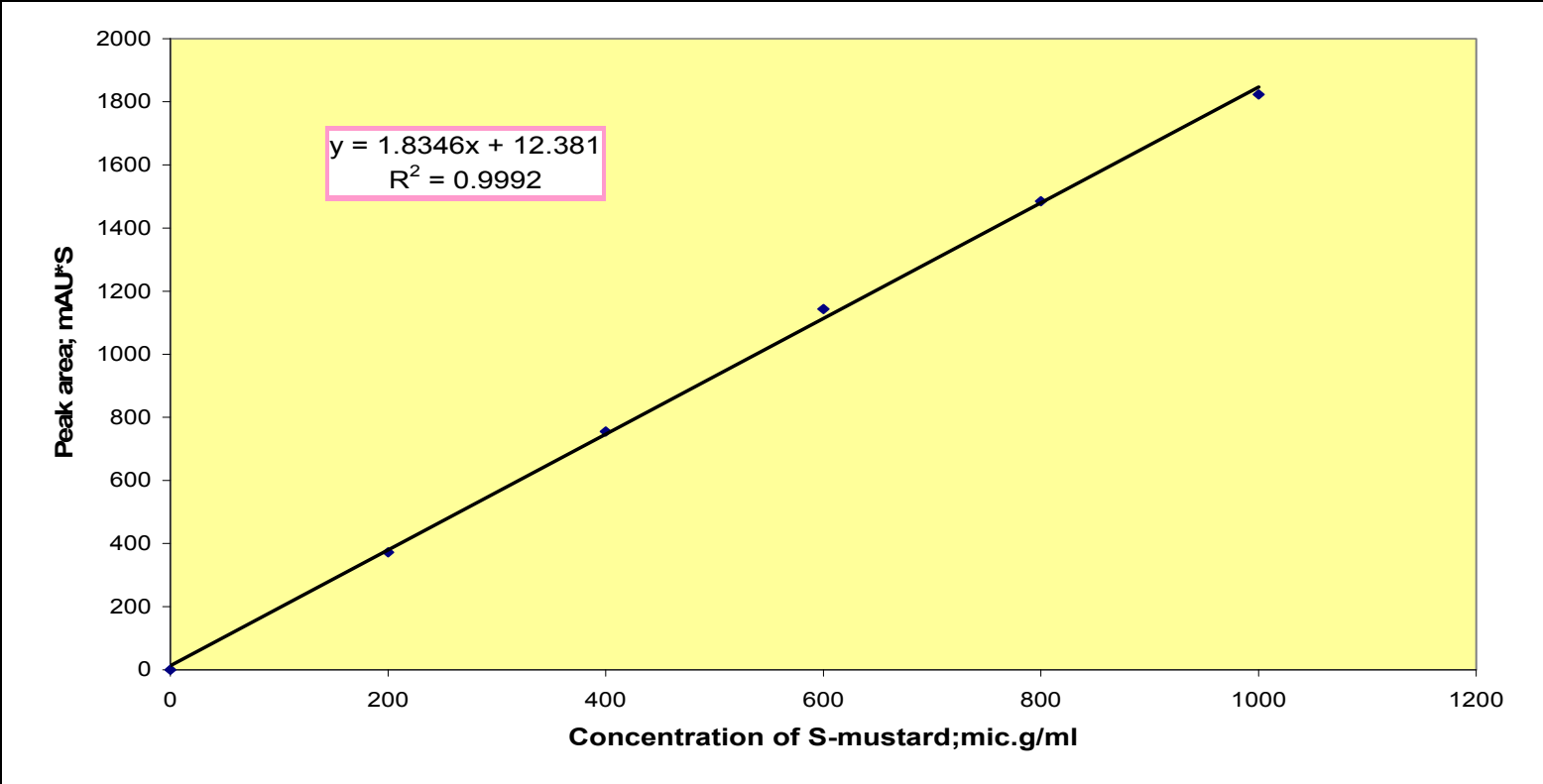

Fig.(4) Calibration curve of S-mustard in ethanol obtained over the concentration range (200-1000) $\mu \mathrm{g} / \mathrm{mL}$ using HPLC 


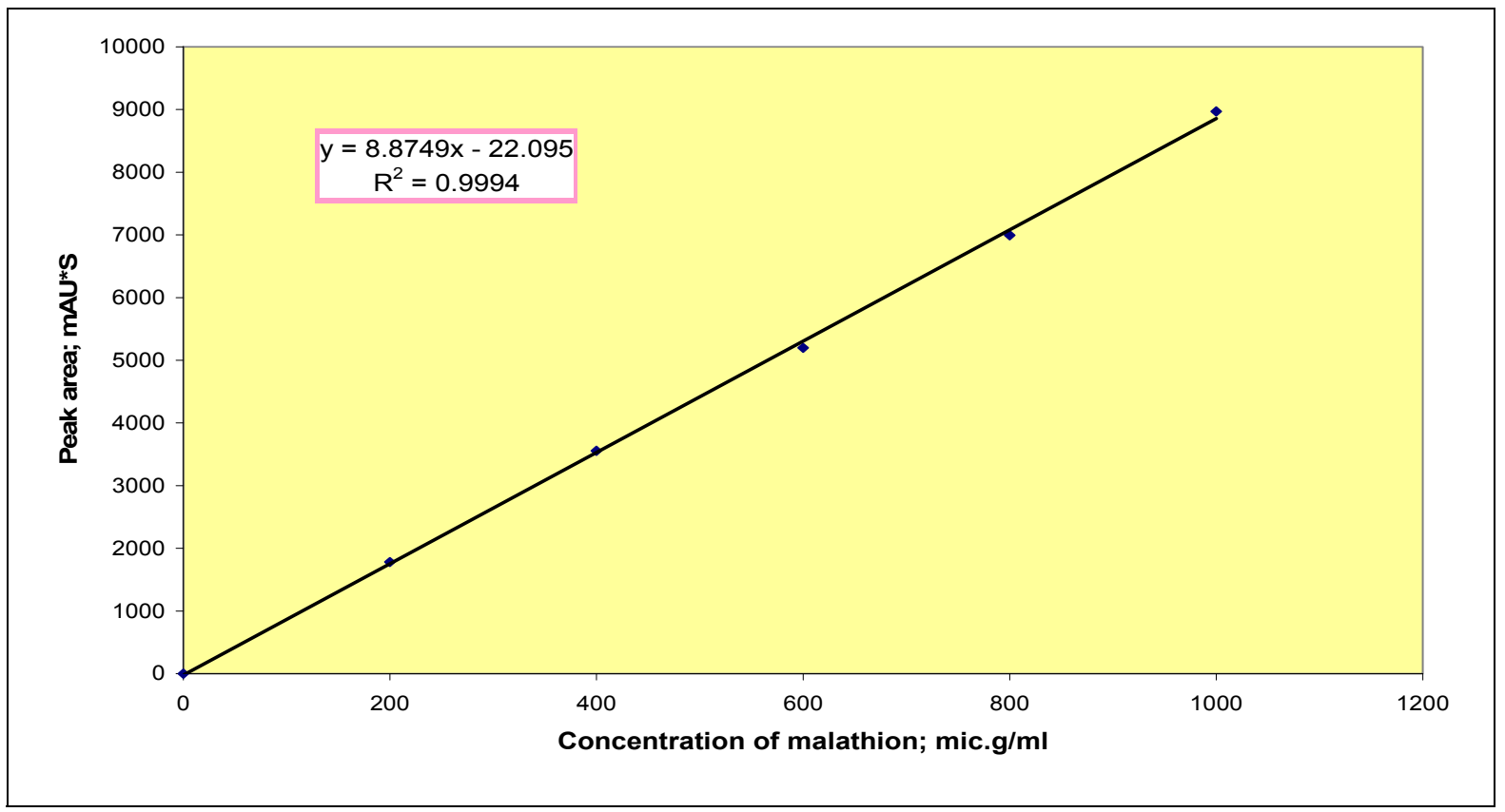

Fig.(5) Calibration curve for Malathion in ethanol obtained over the concentration range (200-1000) $\mu \mathrm{g} / \mathrm{mL}$ using HPLC

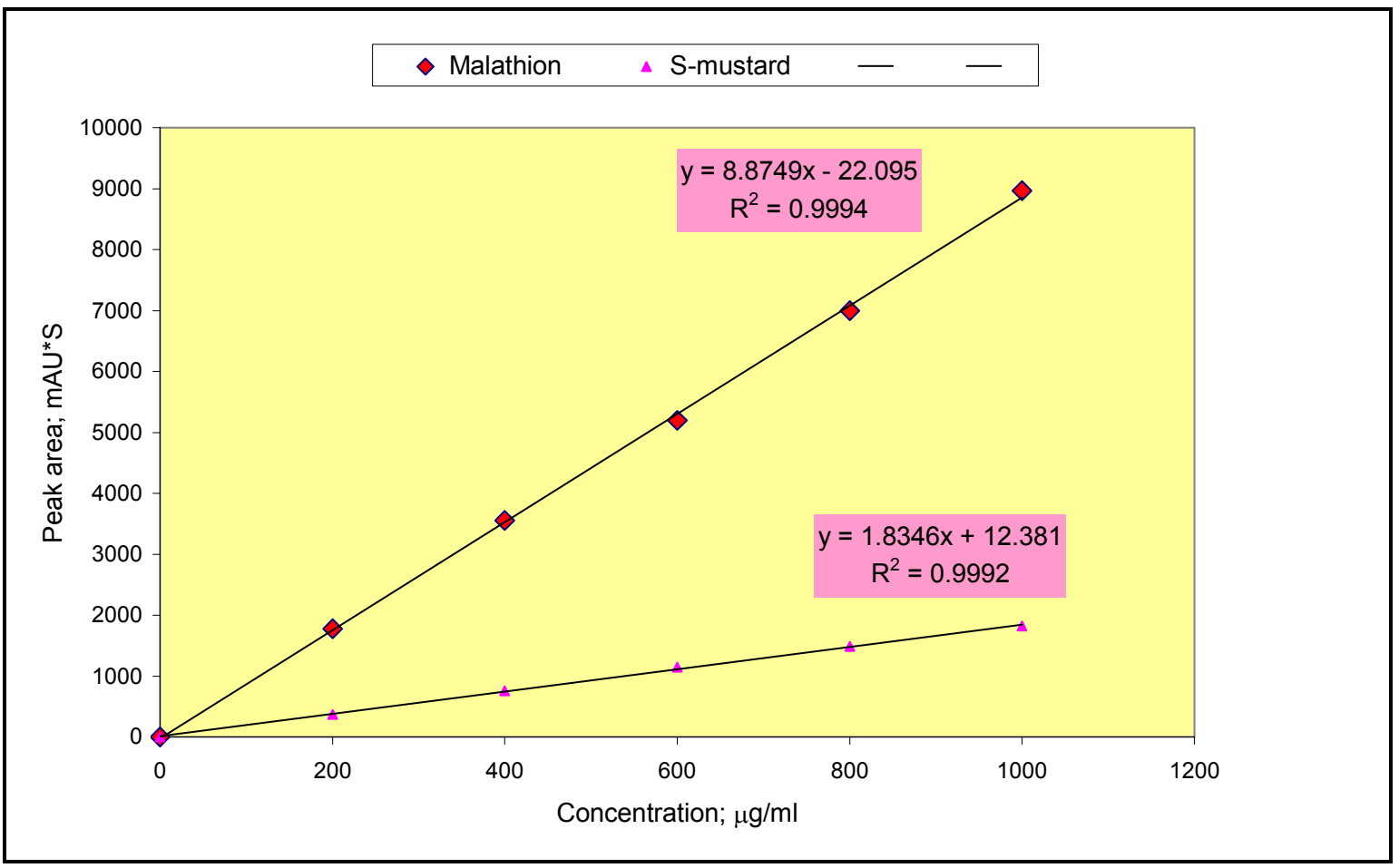

Fig.(6) Calibration curve for both Malathion and S-mustard in ethanol obtained over the concentration range (200-1000) $\mathrm{gg} / \mathrm{mL}$ using HPLC. 